\title{
Chemical Characteristics, Therapeutic Uses, and Legal Aspects of the Cannabinoids of Cannabis sativa: A Review
}

\author{
Hebert Jair Barrales-Cureño ${ }^{1 *}$ \\ https://orcid.org/0000-0002-8431-2102 \\ Luis Germán López-Valdez ${ }^{2}$ \\ https://orcid.org/0000-0002-3238-5035 \\ César Reyes ${ }^{3}$ \\ https://orcid.org/0000-0001-9016-8672
}

\author{
Irma Vasquez-García ${ }^{3}$ \\ https://orcid.org/0000-0001-6302-7268
}

\author{
Oscar Francisco Diaz-Lira ${ }^{3}$ \\ https://orcid.org/0000-0003-2630-0995 \\ Braulio Edgar Herrera-Cabrera ${ }^{5}$ \\ https://orcid.org/0000-0001-9670-8721
}

\section{Victor Manuel Cetina-Alcalá \\ https://orcid.org/0000-0003-4417-5059}

1 Universidad Michoacana de San Nicolás de Hidalgo, Instituto de Investigaciones Químico-Biológicas, Departamento de Biotecnología Vegetal, Morelia, Michoacan, Mexico; 'Universidad Autónoma Chapingo, Laboratorio de Productos Naturales, Área de Química. Texcoco, Estado de Mexico, Mexico; ${ }^{3}$ Universidad Intercultural del Estado de Puebla. Lipuntahuaca, Huehuetla, Puebla; ${ }^{4}$ Colegio de Postgraduados, Campus Montecillo, Texcoco, Estado de México, Mexico; ${ }^{5}$ Colegio de Postgraduados, Campus Puebla, Puebla, Mexico.

Received: 2019.04.07; Accepted: 2020.03.17.

*Correspondence: hebert.jair@uiep.edu.mx; Tel.: 917+1437167 (58030).

\section{HIGHLIGHTS}

- Cannabis sativa is a plant with psychoactive properties.

- Marijuana contains 421 active compounds, of which 60 are so-called cannabinoids.

- The main psychoactive substance in marijuana is $\delta$-9-tetrahydrocannabinol.

Abstract: Marijuana (Cannabis sativa) is an important annual medicinal plant that belongs to the Cannabaceae family. It contains 421 substances of 18 chemical types-the most significant compound is $\delta$ 9-tetrahydrocannabinol, which causes several effects, both in the Central Nervous System and in several peripheral locations in the organism. The objectives of this scientific review are to mention the anatomical distribution, chemical characteristics and biosynthesis of cannabinoids, as well as its actions mechanisms. The endogenous cannabinoid system, the therapeutic properties of $C$. sativa and its action on the nociceptive control are described. Finally, the modulators of the cannabinoid system in clinical use are indicated, together with marijuana legalization benefits.

Keywords: anandamide; biosynthesis; $\delta 9$-tetrahydrocannabinol.

\section{INTRODUCTION}

Marijuana (Cannabis sativa) is an herbaceous, dioicous, annual plant that belongs to the Cannabaceae family. It grows in tropical and subtropical regions [1]. This family includes several species, among which $C$. produces the highest amount and concentration of active principles; $C$. indica mainly produces fibers and oil-both species have psychoactive properties [2]. The route of administration is inhalation (intrapulmonary $\mathrm{u}$ oral), and its modes of presentation are of two: first, as plant (a ground mixture of leaves, stems, and female 
floral units or buds), with 5 to $15 \%$ of $\delta 9$-tetrahydrocannabinol ( $\delta 9-\mathrm{THC})$; the countries with higher production of this presentation are Mexico, Colombia, Jamaica and USA; secondly, in form of hashish (dry extract of the resin), whose content of $\delta 9-\mathrm{THC}$ is 10 to $20 \%$; the greatest producers are Morocco, Afghanistan and Pakistan [3]. Its resin is a yellow and sticky substance that contains the active ingredients. Marijuana contains 421 substances of 18 chemical types-its most important chemical compound is the delta-9-tetrahydrocannabinol that has synergistic effects with other cannabinoids and cannabinols [4]. The therapeutic effects of isolated cannabinoids are used in the treatment of psychotic disorders, anorexia, cachexia, asthma, musculoskeletal disorders, tumoral pathology, arthritis, neuralgias, inflammatory disorders of the gastrointestinal tract, neuropathy, dysmenorrhea, ulcerative colitis, Crohn's disease, in addition, it has antiglaucoma, antiemetic, antiobesity, and anticancer properties [5]. At the clinical level, its efficacy has been assessed in the treatment of neuropathic, oncologic and symptomatic pain in multiple sclerosis in patients unresponsive to usual treatments, epilepsy, spasticity (related to multiple sclerosis), Huntington's disease or medullary lesions, AIDS and terminal cancer, [6,7], glaucoma, nausea, chemotherapy-induced vomiting, itching, allergies, psychiatric symptoms, and motility conditions [8].

It has been determined that the active form of $\delta 9-T H C$ is retained by the body for as long as 45 days after its introduction to the organism. It is stored in liver, lungs, and testicles, gradually disappearing from these organs that are the most susceptible to damage. Endogenous cannabinoids or endocannabinoids are a family of molecules produced by any eukaryote tested. Chemically, they are derived from arachidonic acid. Its main representatives are anandamide and 2-arachidonoylglycerol. During brain development, cannabinoids participate in the regulation of motor activity, learning, memory and nociception. This is determined from the distribution of endocannabinoids and CB1 receptors in the brain, in such a way that the distribution of these receptors in different brain structures has a relationship to the physiological processes in the Central Nervous System (CNS) [9].

Cannabinoids show different degrees of affinity for CB1 and CB2 receptors. Synthetic cannabinoids that act as selective agonists or antagonists to either receptor have been developed. $89-\mathrm{THC}$ has an equal affinity to both receptors, while anandamide has a very low selectivity for CB1 receptors. However, the efficacy of 89-THC and anandamide is lower in CB2 than in CB1 receptors [10]. In 1986, the FDA authorized the medicinal use of $\delta 9-\mathrm{THC}$ to treat nausea and vomiting, secondary effects in chemotherapy patients [11]. On the other hand, there is a great debate over marijuana legalization in Mexico. In fact, several European countries and some states of the USA have underwent legalization due to its clinical benefits; the biotechnological production of in vitro cultures could generate cannabinoids exclusive for medicinal use. Marijuana ingested orally (or rectally) has important therapeutic properties, especially in terminal phase patients; in fact, it could be considered the first actually useful anti-suffering drug [12]. It is worth saying that the medicinal use of marijuana is legal in some countries, among them, Germany, Argentina, Austria, Canada, Spain, Finland, Portugal and Israel. In contrast, marijuana abuse during adolescence negatively affects neuronal circuit maturation and increases the risk of suffering mental disorders. Because of the health risks, especially in children and young adults, its legalization is not justified. Thus, the objective of this scientific review is to point out the generalities of $C$. sativa, with mention of its anatomical distribution, chemical characteristics, and cannabinoid biosynthesis, as well as its mechanism of action. Lastly, the modulators of the cannabinoid system in clinical use are indicated, as well as some benefits of marijuana legalization as a necessary step to justify its usefulness against different diseases.

\section{General characteristics of Cannabis sativa}

Marijuana is a dioicous (with separate sexes-male stem and female stem), annual plant, resistant to climatic changes, except to freezing. It has a height of 1.6 to 6 meters. The female plants are more leafy and long-lived. Its leaves have an elongated form with indented edge, dark green in color, with a lighter back, and its surface is covered by secretory hairs more numerous in the back and arranged in the form of a palm with 5-7 leaves, with the longest one in the center. The male plant has a pollen-producing flower apex, while the female flowers are smaller. Their ovaries are sheathed in bracts (foliar organs in the proximity of flowers and different to normal leaves - they don't photosynthesize, since its function is to protect flowers) of color green and they are not pollinated by insects but by wind. The male plant dies shortly after having scattered the pollen, while the female flower survives until seed maturity or exposition to low temperatures. Resin acts as a natural varnish, covering leaves and stems to protect them from dessication, under the conditions of high temperatures and low humidity in which the plant usually grows [13]. 


\section{Anatomical distribution of cannabinoids}

The number and concentration of chemical compounds in Cannabis varies with genotype, climate, type of soil, mode of preparation, and with different cultivation types, which go from garden and pots (natural or artificial light) to hydroponic techniques [14]. Cannabinoid production occurs in the epidermal glandular trichomes [15], which show variations with respect to size, form, and population density as a function of the examined regional anatomical configuration. There are no published reports yet of gland trichomes being present in the surface of roots, but only in aerial parts, together with non-glandular trichomes. These epidermal glandular trichomes are divided in two categories: stem and sessile. "Stem" gland trichomes have one cell or a small group of cells arranged in a Rosetta formation in one-celled or multi-cellular pedestal. This variation is attributed to the observation of different developmental stages (ontogeny). The stem-less sessile glandular trichomes have secretory cells located under the epidermal surface. In any case, gland cells are covered with a "sheath" in which the resins are secreted through vesicles. This sheath consists of a cuticle covering a polysaccharide layer (cellulose) from the primary cell wall. The resins accumulate until the sheath protrudes from the secretory cells, forming an spheroidal structure, and is released by the breaking of the membrane or through pores in its surface. Cannabinoid content in each part of the plant varies in parallel to the distribution of the observable gland [16]. The roots have only trace amounts. In contrast, stems and branches have larger quantities, although not so much as leaf. Vegetative leaves contain variable quantities in function of its position in the plant-the lower ones have less content and the upper ones more content; the same is true for apical meristems. Leaf glandular trichomes are denser in the abaxial (lower) part than in the surface. Once sexual differentiation occurs, the production of female reproductive organs and its associated bracts increases total cannabinoid content. Bracts that underlie female flowers contain a higher gland density than leaves. The small cup-shaped bract (perigonal) enclosing the pistil has a higher cannabinoid content than any other part of the plant. The male reproductive structures and the achenia yield low cannabinoid concentrations, while the highest amount is found in non-germinated female flowers.

\section{Chemical characteristics of cannabinoids}

The term "phytocannabinoid" has been proposed for the natural components of the plant and "endocannabinoid" for the components synthesized in animals and humans that are the endogenous ligands for cannabinoid receptors [17] cannabinoids in plants are substances that show a carbocyclic structure with 21 carbon atoms and are usually formed by three rings: cyclohexene, tetrahydropirane and benzene. Cannabinoids contain aromatic oxygenated hydrocarbons and do not contain nitrogen. $\delta 9$-thc is the cannabinoid responsible for the main psychoactive effects of many pharmacological products. in some Cannabis varieties, the additional cannabinoid homologues substitute the pentyl group usually joined to the aromatic ring with a propyl. Chemical composition of $C$. sativa is complex because it contains four hundred chemical products (mono- and sesquiterpenes, sugars, hydrocarbons, steroids, flavonoids, nitrogenated complexes and amino acids, and a total of sixty six cannabinoids, with $\delta 9-\mathrm{THC}$ as the psychostimulant in highest proportion. the main cannabinoids are $\delta 9$-tetrahydrocannabinol, $\delta$-8-tetrahydrocannabinol ( $\delta 8-\mathrm{THC})$, cannabidiol (CBD) and cannabinol (CBN). Other cannabinoids present in the plant are cannabichromene $(\mathrm{CBC})$, cannabiciclol (CBL), cannabigerol (CBG), cannabigerol monomethyl ether (CBGM), cannabielsoin (CBE), cannabinodiol (CBND), cannabitriol (CBT), dehydrocannabifuran, and cannabicitran, that appear in variable amounts according to the Cannabis variety (Figure 1).

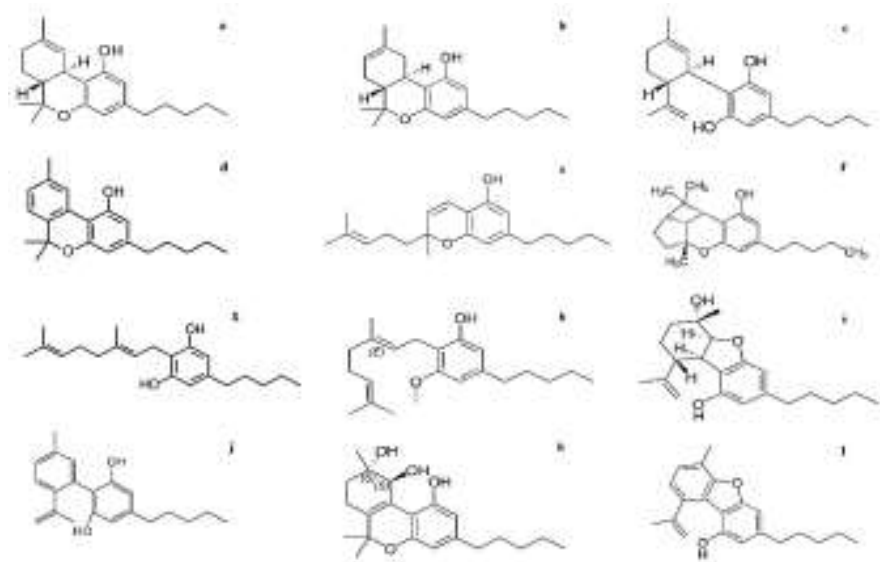

Figure 1. Cannabinoids principal in C. sativa. a) $\delta 9$-tetrahydrocannabinol ( $\delta 9-\mathrm{THC}, \mathrm{C}_{21} \mathrm{H}_{30} \mathrm{O}_{2}, 314.45 \mathrm{~g} / \mathrm{mol}$ ); b) $\delta$-8tetrahydrocannabinol ( $\delta 8-\mathrm{THC}, \mathrm{C}_{21} \mathrm{H}_{30} \mathrm{O}_{2}, 314.46 \mathrm{~g} / \mathrm{mol}$ ); c) cannabidiol (CBD, $\mathrm{C}_{21} \mathrm{H}_{30} \mathrm{O}_{2}, 314.46 \mathrm{~g} / \mathrm{mol}$ ); d) cannabinol (CBN, $\mathrm{C}_{21} \mathrm{H}_{26} \mathrm{O}_{2}, 310.43 \mathrm{~g} / \mathrm{mol}$ ); e) cannabichromene (CBC, $\mathrm{C}_{21} \mathrm{H}_{30} \mathrm{O}_{2}, 314.46 \mathrm{~g} / \mathrm{mol}$ ); f) cannabiciclol (CBL, $\mathrm{C}_{21} \mathrm{H}_{30} \mathrm{O}_{2}$, 
$314.46 \mathrm{~g} / \mathrm{mol}) ; \mathrm{g})$ cannabigerol ( $\left.\left.\mathrm{CBG}, \mathrm{C}_{21} \mathrm{H}_{32} \mathrm{O}_{2}, 316.48 \mathrm{~g} / \mathrm{mol}\right) ; \mathrm{h}\right)$ cannabigerol monomethyl ether $\left(\mathrm{CBGM} \mathrm{C}_{23} \mathrm{H}_{34} \mathrm{O}_{4}\right.$ $374.5 \mathrm{~g} / \mathrm{mol})$; i) cannabielsoin $\left(\mathrm{CBE}, \mathrm{C}_{21} \mathrm{H}_{30} \mathrm{O}_{3}, 330.46 \mathrm{~g} / \mathrm{mol}\right) ; \mathrm{j}$ ) cannabinodiol (CBND, $\mathrm{C}_{21} \mathrm{H}_{26} \mathrm{O}_{2}, 310.43 \mathrm{~g} / \mathrm{mol}$ ); $\mathrm{k}$ ) cannabitriol (CBT, $\left.\mathrm{C}_{21} \mathrm{H}_{30} \mathrm{O}_{4}, 346.46 \mathrm{~g} / \mathrm{mol}\right)$; I) dehydrocannabifuran, (DHC, $\mathrm{C}_{21} \mathrm{H}_{24} \mathrm{O}_{2}, 308.41 \mathrm{~g} / \mathrm{mol}$ ) and $\mathrm{m}$ ) cannabicitran ( $\left.\mathrm{CBN}, \mathrm{C}_{21} \mathrm{H}_{30} \mathrm{O}_{2}, 314.5 \mathrm{~g} / \mathrm{mol}\right)$.

C. sativa has a $\delta 9$-thc concentration ranging from 0.5 to $5 \%$, while hashish contains 2 to $20 \%$ (hall and degenhardt, 2009). cannabidiolic acid, with antibiotic activity, is an important constituent of fiber-type hemp [18] 89 -thc is the cannabinoid with the highest psychoactive potency and because of its hydrophobic properties it is soluble in lipids. $\delta 8$-thc has a pharmacological profile similar to $\delta 9$-thc, although its effects are markedly weaker and are found in some varieties in low concentration. Cannabinol (CBN) has psychoactive properties that are a tenth part of those described for THC, and shows a higher affinity for the CB2 receptor than for CB1. Cannabidiol (CBD) is a bicyclic compound, being in the split tetrahydropyran ring, virtually has no psychoactive properties, which is why its potential clinical effects are investigated. Thus, CBD treatment in humans attenuates some of the psychological alterations from high doses of $\delta 9-\mathrm{THC}\left(0.5 \mathrm{mg} \mathrm{kg}^{-1}\right)$; for example, it reduces anxiety and panic [19]. The knowledge of the relationship between cannabinoid structure and activity permitted the design of analog compounds with great usefulness in pharmacology and physiology. In some cases, its hydrophobic nature was modified to increase solubility in water, or the affinity for the receptor was increased. In addition, structural modifications permitted the preparation of by-products related to some of the activities attributed to these compounds, avoiding their psychotropic effects. In the late 80 s, the first synthetic cannabinoids were designed, and showed pharmacological profiles similar to the natural ones used in cannabinoid receptor characterization. The agonist molecules are response activators of cannabinoid receptors, for example, the 11-hydroxy- $88-T H C-D M H ~(H U-210)$ is the most potent synthetic cannabinoid currently known due to the presence of a hydroxyl group in C11 and a 1,1-dimethylheptyl in its lateral chain, and it helped in anandamide characterization, the first endogenous cannabinoid isolated from the brain. The antagonists molecules are able to prevent or reverse the actions of the agonists acting through $\mathrm{CB} 1$, both in vivo and in vitro. Because of this, research centered around the structural modification of natural analogs has produced five useful classifications. 1.- Natural: lipidic mediators (between 19 and 21 carbon atoms of tricyclic nature), contain ether and hydroxyl groups; 2.- Modified natural: molecular systems and pharmacological entities generated from secondary metabolites and structural analogs with potential pharmacological action of the cannabinoid type for its interactions with $\mathrm{CB}_{1}$ and $\mathrm{CB}_{2}$ receptors; 3.- Classic synthetic: they maintain the natural annular cannabinoid structure and the oxygen atoms, 4.- Non-classic synthetic: molecules whose reorganization, addition, or elimination with respect to the prototypical structures is radical, or that have the isosteric replacement of an atomic substitute and 5.- Endogenous: lipidic structures between 12 and 18 carbon atoms that are characterized by 3-4 insaturations and that constitute biosynthetic endogenous precursors of local release, whose concentrations depend on the physiological environment $[20,21,22]$. Among the main phytochemical constituents of $C$. sativa are terpenoids such as myrcene $(67 \%)$ and limonene (16\%). The most abundant monoterpens are $\beta$-myrcene, $\alpha$-pinene, trans-ocimene, $\alpha$ terpinolene and sesquiterpene trans-caryophyllene. In the essential oils of five different European cultivars of Cannabis, the dominant terpens are myrcene (21.1-35.0\%), a-pinene (7.2-14.6\%), a-terpinolene (7.0$16.6 \%)$, trans-caryophyllene (12.2-18.9\%) and a-humulen (6.1-8.7\%) [23]. Other terpenoids present in only trace amounts are sabinene, $\alpha$-terpinene, 1,8-cineole (eucalyptol), pulegone, $\gamma$-terpinene, terpineol-4-ol, bornyl acetate, $\alpha$-copaene, alloaromadendrene, viridiflorene, $\beta$-bisabolene, $\gamma$-cadinene, trans- $\beta$-farnesene, trans-nerolidol, and $\beta$-bisabolol [24]. In respect to hydrocarbon content, fifty hydrocarbons have been detected in Cannabis ranging from $\mathrm{C}_{9}$ to $\mathrm{C}_{39}$, 2-methyl, 3-methyl, and sometimes dimethyl alkanes. The main alkanes present in the essential oil obtained by extraction and steam distillation are $\mathrm{n}-\mathrm{C}_{29}$ alkane nonacosane (55.8 and $10.7 \%$, respectively), heptacosane, 2,6-dimethyltetradecane, pentacosane, hexacosane, and hentriacontane.

\section{Biosynthesis of cannabinoids}

Cannabinoid biosynthesis occurs in the glandular trichomes of $C$. sativa flowers. Cannabinoids are prenylated polyketides derived from fatty acids and isoprenyl precursors, although the pathway is not completely elucidated at the molecular level. Recent research has determined that the first proposed enzyme for the cannabinoid pathway is the polyketide synthase III (PKS), which catalyzes the condensation of hexanoyl-CoA with three molecules of malonyl-CoA to form the olivetolic acid (OA) [25]. This aldol cyclization reaction $\mathrm{C} 2 \rightarrow \mathrm{C} 7$ is necessary for retaining the carboxylated molecule, which is rare in plant polyketides. Olivetolic acid is geranylated to form cannabigerolic acid (CBGA), which is transformed into the main cannabinoid, 89 -THC, and cannabidiolic acid (CBDA) through oxydocyclase enzymes. $89-\mathrm{THC}$ and CBDA 
undergo a non-enzymatic decarboxylation into its neutral forms, THC and cannabidiol (CBD), respectively (Figure 2) [26].

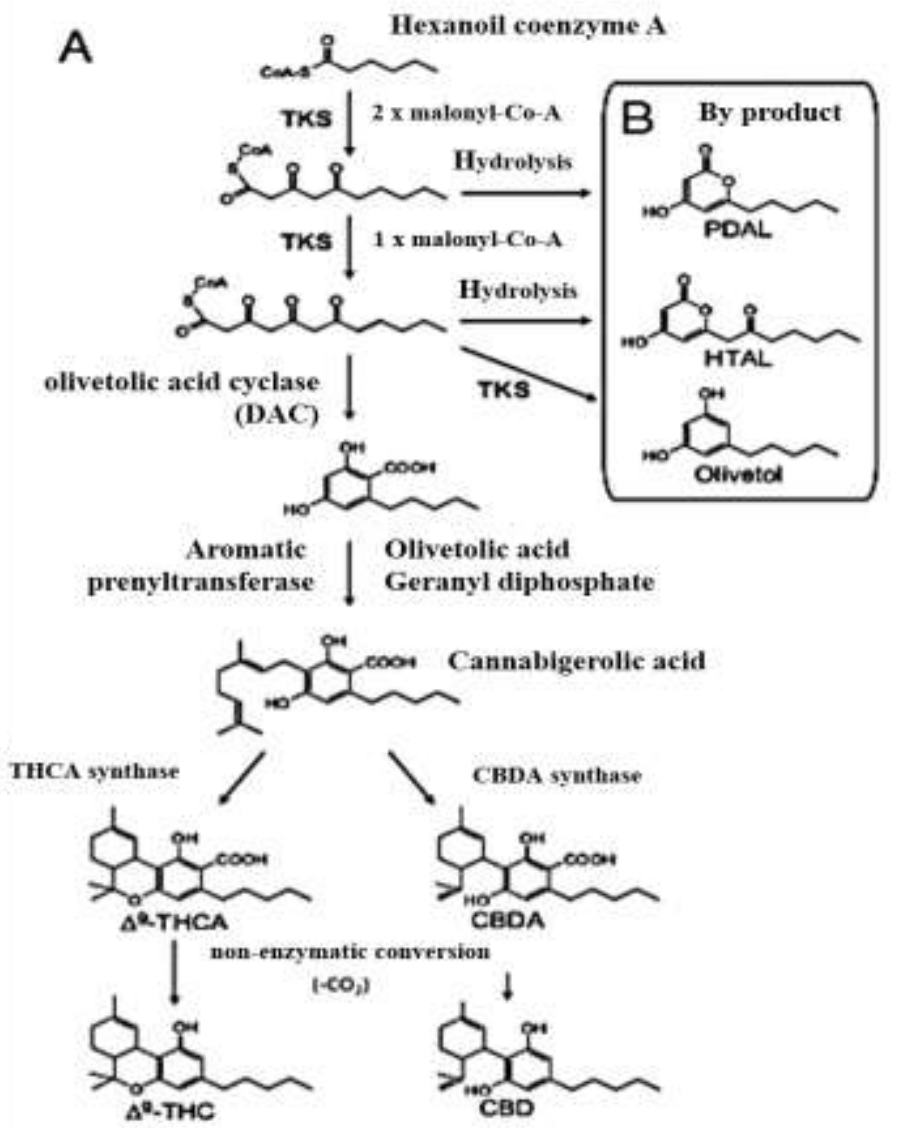

Figure 2. Biosynthetic route of the cannabinoids of $C$. sativa. A). The route begins with the main cannabinoid acid $\delta 9$ tetrahydrocannabinolic acid (ס9-THC) and cannabidylic acid (CBDA), which is decarboxylated to $\delta 9$ tetrahydrocannabinol (THC) and cannabidiol (CBD, respectively. B). The recombinant enzyme TKS produces tricetides (PDAL) and tetracetydes (HTAL and olivetol) by in vitro products [25].

\section{Endogenous cannabinoid system and action mechanism}

The characterization of the structure of substances is the initial step for elucidating the action mechanisms of said substances. In 1964, the metabolite of 89 -THC was isolated and identified, which led to the discovery in the 1990s of the endocannabinoid system and protein receptors CB1 and CB2, 472-473 and 360 amino acids in size, respectively [27]. The known acting routs of cannabinoids are mediated by two types of receptors coupled to Gi proteins distributed in the CNS, in regions involved in motor coordination, memory, reward system, effects on tumoral cells brain areas that process nociceptive information, among others. CB1 receptors are located in the CNS and in the testicles, while CB2 receptors are found in the immune system and other tissues [28]. Its functional activity was identified through neuroimaging tools for brain metabolism [29]. The cannabinoid receptors CB1 were the first to be cloned and identified [30]. They are located in the CNS, in the periphery of the brain cortex, basal ganglia, cerebellum, and hippocampus in abundance [31].

\section{Cannabinoid Receptors in the Central Nervous System: Their Signaling and Roles in Disease}

The identification of cannabinoid receptors allowed for the discovery of their endogenous ligands, known as endocannabinoids. They act in the brain as neuromodulators. The central cannabinoid receptor is expressed in pre-synaptic neurons. Thus, endogenous production is local, that is, close to the action site [32]. Cannabinoids, both endogenous and exogenous, bind to receptors and cause a cell response. All the endocannabinoids are synthesized from membrane lipids (polyunsaturated fatty acids), which makes them different in its chemical structure to plant phytocannabinoids [33]. Among the endocannabinoids identified so far are anandamide ( $\mathrm{N}$-arachidonoyl-ethanolamide, AEA), 2-arachidonoyl-glycerol (2-AG), 2-arachidonoylglycerol ether (noladin ether), O-arachidonoyl-ethanolamine (virodhamine) and $\mathrm{N}$-arachidonoyl-dopamine (NADA) [34]. First two endocannabinoids ever discovered, anandamide and 2-AG, are the most studied ones. They have a chemical structure different to $89-\mathrm{THC}$ and lack its psychotropic properties [35]. In contrast to other chemical signals in the brain, they are not synthesized nor stored in vesicles, as it is the case of other 
neurotransmitters deposited in brain cells-rather, they are generated from precursors and released on demand [36]. Endocannabinoids are produced as a consequence of increases in intracellular $\mathrm{Ca}^{2+}$ and they interact with CB1 receptors located in pre-synaptic neurons, modulating the release of neurotransmitters (NT), like dopamine. These in turn activate ionotropic (iR) and metabotropic (mR) receptors [37]. Once released, the endocannabinoids are deactivated quickly through cell re-uptake and metabolization. The endocannabinoids are removed from the synaptic space by a specific transporter $(T)$, once they are in the cytoplasm [38]. Anandamide and 2-AG metabolism mainly occurs by enzymatic hydrolysis by fatty acid amido hydrolase (FAAH) on ethanolamine (Et) and arachidonic acid (AA), and monoacylglycerol-lipase (only in the case of 2-AG) [39].The functions of cannabinoids in the organism help the modulation of neuro-transmission in order to exert the characteristic physiological effects regulating several physiological processes (Table 1).

Table 1. Main physiological systems whose regulation is influenced by the endocannabinoid system [38,39].

\section{System}

\begin{tabular}{cc}
\hline Respiratory system & Bronchial relaxation \\
\hline Physiological system & Endo cannabinoids function \\
\hline Cardiovascular system & Arterial pressure \\
\hline Gastrointestinal system & Gastric emptying \\
\hline Skeletal system & Bone formation \\
\hline Reproductive system & Spermatic implantation and motiliy \\
\hline Immune system & Cytokine inflammation and release \\
\hline Periphal nervous system & Neurigenic inflammation and nociception \\
\hline aypothalamus-hypophysis-adrenal & Corticosteroid reléase and stress response \\
\hline Central nervous system & Learning and memory, emotion, neuronal excitability, \\
& intake, locomotion, motivation, nociception, and synaptic \\
& plasticity
\end{tabular}

\section{Therapeutic properties of $C$. sativa}

In the present, the use of cannabinoid derivatives for the treatment of several pathologies is a serious possibility, thanks to the isolation and identification of $89-\mathrm{THC}$ [40] and the endocannabinoid system, receptors, enzymatic systems, and physiological effects. The therapeutic effects of isolated cannabinoids are used in psychotic conditions, anxiety, depression, anorexia, cachexia, asthma (bronchodilation action), pain, musculoskeletal diseases, tumoral pathologies, arthritis, neuralgias, dysmenorrhea, ulcerative colitis, Crohn's disease [41]. and additionally they have antiglaucoma, antiemetic, antiobesity, and anticancer properties [42]. At the clinical level, its efficacy has been assessed in the treatment of neuropathic, oncologic and symptomatic pain in multiple sclerosis in patients unresponsive to usual treatments, epilepsy, spasticity (related to multiple sclerosis), Huntington's disease or medullary lesions, AIDS and terminal cancer, [43,44], glaucoma, nausea, chemotherapy-induced vomiting, itching, allergies, psychiatric symptoms, and motility conditions $\delta 9-\mathrm{THC}$ metabolism occurs by hydroxylation, glucuronidation, and oxidation processes mediated by enzymes of the cytochrome p450 system in the liver. The main subfamily involved is CYP2C. Approximately one hundred metabolites of THC have been identified-most of them are monohydroxylated [45]. In addition, cannabinoids have interaction with several neurotransmitters and neuromodulators, such as gamma aminobutyric acid (GABA), histamine, serotonin, dopamine, glutamate, norepinephrine, prostaglandins, and opioid peptides. Cannabis extracts contain $3-5 \%$ of $\delta 9-T H C$, CBN, and CBD, which increases the permeability of the hematoencephalic barrier by making the entry into the brain easier [46]. Entry and distribution of $\delta 9-\mathrm{THC}$ in blood and tissues is quick, with a kinetics similar to the one obtained after its intravenous administration [47]. Only $3 \%$ of the $\delta 9-\mathrm{THC}$ present in blood is in free form. Due to its high hydrophobicity, it binds to different plasmatic components. $9 \%$ binds to blood cells, $60 \%$ to plasmatic lipoproteins and the rest to albumin. This property explains its quick penetration in tissues of vascularized organs-lungs, liver, kidney, heart, stomach, spleen, adipose tissue, placenta, adrenal cortex, thyroid, pituitary, and mammary gland. Subsequently, it moves into fatty tissue, that together with the spleen are its major storage sites three days after its intake [48,49]. The drug can persist for several weeks before its 
elimination as free acid or as conjugate with glucoronic acid, after its administration ceases. On the other hand, research lines have shown the capacity of cannabinoids to provoke cell apoptosis (programmed cell death). In animal assays, $\delta 9-\mathrm{THC}$ and a synthetic agonist, WIN-55,212-2, have been observed to reduce and disappear malignant gliomas, one of the most dangerous brain tumors known to date. Other studies show the antiproliferative effect of anandamide in breast cancer, and it is also mediated by cannabinoid receptors in the kinase A and MAPkinases (MAPK) pathways. The knowledge of the endocannabinoid system allows us to know the regulation of several processes involved in the development of cancer progression. Cannabinoids are potent anticancer agents against lung cancer [50], gliomas [51, 52, 53, 54], thyroid epithelioma [55], lymphoma/leukemia skin carcinoma [56], uterus [57 58], breast [59; 60, 61], prostate [62 63], and colon cancers [64 65], as well as neuroblastoma [66], which is why cannabinoid production by in vitro culture biotechnology would produce a sustainable and viable alternative. Cannabinoids exert a direct anti-proliferative effect on tumors of different origin. They have been shown to be anti-migratory and antiinvasive and inhibit MMPs which in turn degrade the extra-cellular matrix (ECM), thus affecting metastasis of cancer to the distant organs [67].

\section{THC metabolism}

The elimination mechanisms of $89-\mathrm{THC}$ are well known in both experimental animals and humans. Only a minimal amount of this compound is eliminated from the body in its original form, while most of it appears in the form of metabolites in faeces $(68 \%)$ or in urine (12\%). The drug is also present in other tissues and biological fluids such as hair, saliva and sweat. Most metabolism occurs in the liver, although it can also occur in other organs such as the lung and intestine. In chronic marijuana smokers there is a significant increase in the amount of urine secreted [68]. In the urine there is an appreciable presence of $11 \mathrm{OH}-\mathrm{THC}$ and a high concentration of THC-11-oic acid, both in free or conjugated form [69]. The concentration of THC-11-oic acid present in human urine does not show an appreciable correlation with that present in blood, although it seems to improve when the logarithms of these concentrations are compared [70]. Regarding the reactions involved in their catabolism, $89-\mathrm{THC}$ and $88-\mathrm{THC}$ follow a very similar path of degradation [71]. The first enzyme to act is cytochrome P-450, which oxidizes the corresponding cannabinoid to mono-, di- or trihydroxylated derivatives [72]. $89-\mathrm{THC}$ and $\delta 8-\mathrm{THC}$ are rapidly hydroxylated to 11-hydroxy- $89 \mathrm{THC}$ and 11-hydroxy- $\delta 8$ THC, respectively, in the liver [73]. The hydroxylation pattern reflects the isoform distribution of cytochrome P-450. Thus, in humans, the isoform P450 2C9 hydroxylates THC in 11, P450 3A hydroxylates THC in 8 and, in the monkey, P450 RM-A hydroxylates THC in 11 and 8, while P450 JM-C hydroxylates THC in 3'. Hydroxylation can occur at more than eight different sites $\left(1^{\prime}, 2^{\prime}, 3^{\prime}, 4^{\prime}, 5^{\prime}, 8 \alpha, 8 \beta\right.$ and 11) where the relative proportion varies between species, which may be related to differences between species of cytochrome P450. Hydroxylation at position 11 is the most important reaction of the metabolism of $\delta 9-\mathrm{THC}$ in most species including humans. The 11-hydroxy- $89-\mathrm{THC}$ has a similar pharmacological activity and potency to $\delta 9-\mathrm{THC}$. This compound can be oxidized to the corresponding carboxylic acid (ס9-THC-11-oic acid) or rehydroxylated. In the second case, it becomes 8,11-dihydroxy- $89-\mathrm{THC}$, which can be hydroxylated in the lateral chain. These hydroxylated compounds are subsequently transformed into other, more polar metabolites by breaking of the lateral chain and oxidation to the corresponding carboxylic acid. It is also possible to reduce the double bond of THC, resulting in the corresponding hexahidrocannabinol, which is usually oxidized in C-11. In some cases there is an epoxidation that produces 9a,10a epoxyhexahidrocannabinol. The fact that $\mathrm{CBN}$ and its derivatives have been found in urine and bile from animals administered $89-\mathrm{THC}$ seems to indicate that CBN is a metabolite of $\delta 9-\mathrm{THC}$ [74].

\section{Pharmacological action of cannabinoids in nociceptive control}

Nociception is a sensory somatic modality with a protective function, performed by focusing attention on a harmful stimuli that threatens the integrity of the organism and that must be avoided [78]. In this sense, the cannabinergic system has an important role, given that endogenous and synthetic cannabinoids produce analgesia. The mechanism of signal transduction (the set of processes, reactions, activations, and conformation changes by which a molecule in the outside of a cell causes a response in the interior of the cell) of the cannabinoid binding to those receptors is explained in the following lines. Endogenous cannabinoids are a central and peripheral neuromodulation system because of their action on cannabinoid $\mathrm{CB}_{1}$ and $\mathrm{CB}_{2}$ receptors, which belong to a family of receptors coupled to effectors through $\mathrm{G}$ proteins (that bind to GTP), formed by three types of subunits: $\alpha$ (binds to and hydrolyzes GTP), $\beta$ and $\gamma$. The binding of the agonist to the receptor increases the affinity of the $\alpha$ subunit for GTP [79]. In most of the analyzed tissued, the cannabinoid receptor couples to an effector through an inhibitor $G_{i / 0} G$ protein, and a coupling to $G_{s}$ has also been observed. Another possible effector that regulates the cannabinoid receptor through $\mathrm{G}$ proteins is 
the phospholipase $\mathrm{C}$ enzyme, which hydrolyzes one of the lipids in the plasmatic membrane, inositol phosphatidyl, to split it into two products: diacyl gliceryl (DAG) and phosphate inositol (IP).

The cannabinoid receptor inhibits the adenyl cyclase (AC, catalyzes the conversion of ATP into cyclic AMP (cAMP), increasing the amount of cAMP in the interior of the cell) through the Gi/o a subunit, and decreases in that way intracellular cAMP, which constitutes an activation signal with biological effects [80]. In some cases, the receptor is interacting with $\mathrm{G}_{\mathrm{s}}$ and stimulates the adenylyl cyclase activity by increasing the levels of intracellular Camp [81]. Thus, cannabinoids decrease the feeling of pain by inhibiting the calcium channels that reduce the release of neurotransmitters [81]. In turn, agonist drugs imitate the activity of neurotransmitters by interacting with their receptors, while the agonists reduce or suppress their activity by blocking their receptors. The synthesis of cannabinoid antagonists with analgesic action comparable to opioids rekindles the interest for applications in pain treatment (cancer, migraine, arthritis, severe postoperation pain, and multiple sclerosis). Cannabinoids modulate or inhibit processes related to pain and act in its transmission, which occurs in pain receptors in the spinal cord, and the signal arrives to the brain, where the pain is assimilated at a conscious level. Regarding the brain, the pain stimuli is transmitted from the spinal cord to the thalamus and from there to the amygdala and the somatic sensory brain cortex. $\mathrm{CB}_{1}$ receptors are present in all those areas, and are involved with the modulation of pain transmission throughout the CNS. Antinociception is caused by the activation of cannabinoid receptors, specially $\mathrm{CB}_{1}$, since it has intrinsic psychotropic effects which are inseparable to the antinociceptive action (pain avoiding), which increases patient's quality of life. Regarding the spinal cord, when neuropathic pain occurs, microglia cells secrete inflammatory substances that sensitize neurons, producing pain. These cells have $\mathrm{CB}_{2}$ receptors, where cannabinoids act and in consequence decrease pain. $\mathrm{CB}_{2}$ receptors are involved in antinociception by modulating the release of pro and inflammatory factors of non-neural cells located in the proximity of nociceptive neurons related to the modulation of the immune response $[82,83,84]$. In relation to inflammatory pain, mastocytes are cells that secrete pro-inflammatory substances that sensitize pain receptors. These cells have $C B_{1}$ and $C_{2}$ receptors that upon their activation, a modulation of the secretion of these inflammatory substances occurs, which decreases both inflammation and pain. Clinical studies in humans show that cannabinoids are analgesic substances per se with a potency similar to opioids such as codeine [85]. It is worth noting the presence of $\mathrm{CB}_{1}$ and $\mathrm{CB}_{2}$ cannabinoid receptors in dorsal roots ganglia (DRG), where receptors transported to the periphery through axons are synthesized [86] which constitutes the entry of the nociceptive stimulus into the spinal cord, allowing for the modulation of antinociception at this level. The inconvenient secondary effects of cannabinoid use for pain treatment are related to depression of the CNS, with probable dizziness, disorientation, ataxia, vertigo, disconnection, dry mouth, cloudy vision, and memory alteration [87]. A dose of $5 \mathrm{mg}$ of $\delta 9-\mathrm{THC}$ is tolerable in neuropathic pain without causing alterations in consciousness. In the long term, secondary effects are tolerance and dependence. Chronic use of Cannabis does not produce cognitive alterations, unlike alcohol, but high doses increase up to six-fold the incidence of schizophrenia and other psychosis. This risk seems to be correlated to genetically predisposed individuals and it depends on the amount of Cannabis that under use. High doses produce chronic bronchitis. The pharmacological strategies to enhance the antinociceptive action of cannabinoids limit the apparition of undesirable effects by combining cannabinoid or opioid agents with anandamide re-uptake inhibitors, which enhances analgesic effects and minimizes secondary effects [88]. Lastly, the topical use of cannabinoids enhances the antinociceptive effects of topical morphine [89].

\section{Modulators of the cannabinoid system in clinical use or under research}

Two synthetic agonists of cannabinoid receptors are currently under medical use: 1.- dronabinol, the international generic name of $\delta 9-\mathrm{THC}, 2$.- nabilone, useful both in fybromyalgia-type and neurophatic pain, respectively; a Cannabis extract (Sativex ${ }^{\circledR}$ ), and an antagonist of cannabinoid receptors (rimonabant). In 1985, the FDA (Food and Drug Administration) approved Marinol ${ }^{\circledR}$ pills containing synthetic dronabinol (2.5, $5,10 \mathrm{mg}$ ), produced by Unimed Pharmaceuticals and available in the USA since 1987. Later, in 1992, the FDA approved Marinol ${ }^{\circledR}$ for anorexia associated to weight loss in HIV patients-it is available under prescription in Canada and several European countries. In 2005, the mouth aerosol Sativex ${ }^{\circledR}$, a Cannabis extract applied on mouth mucosa that contains approximately equal parts of dronabinol (THC) and cannabidiol (CBD) was approved in Canada for neurological pain and spasticity in multiple sclerosis [90]. It is made by GW Pharmaceuticals and commercialized in Canada by Bayer Health Care. This compound is under study for its approval as drug in United Kingdom, Spain, Denmark, and the Netherlands. Every day there is more information that suggests that the cannabinoid system is a fundamental mechanism in the regulation of food intake, as well as in the energetic metabolism. Cannabinoid agonists increase appetite, while antagonists have the opposing effect, as observed in studies both in animals and humans. In 2006, rimonabant, an antagonist of cannabinoid receptors, received the approval of the European Medicines 
Agency. It is available in the United Kingdom under the commercial name of Acomplia ${ }^{\circledR}$, and it is used for cessation of tobacco use [91] and even in weight control for those who have stopped smoking and also in obesity, in which case it helps to achieve an improvement in metabolic syndrome in addition to weight loss, with changes in the lipidic and glucidic metabolism that are not observed with the use of other antiobesity drugs currently in use in 2006, Cesamet ${ }^{\circledR}$ pills were approved (synthetic derivative of the dronabinol known as nabilone) for fighting nausea and vomiting provoked by cancer chemotherapy in patients unresponsive to conventional antiemetic treatments [92].

\section{Legal aspects}

Marijuana is the illegal psychoactive substance with the most extended use in the world. The UN estimates that in 2009 between 125 and 203 million people consumed this substance, with an annual prevalence of $2.8-4.5 \%$ of the global total population between 15 and 64 years old [93]. Torres and fiestas Social groups against marijuana legalization note that it is not benign, that it produces irreversible damage in young people, that it shares many of the traits of illegal drugs, that legalization and depenalization will increase its use among young people, and that the social, economic, and health costs will be very high. In addition, in the last 30 years, the complex cultivation of the plant has considerably increased its $\delta 9-\mathrm{THC}$ concentration. In the 1960 s and 1970 s, the $\delta 9-T H C$ content of a marijuana cigarette was $10 \mathrm{mg}$. Today, a cigarette produced by special techniques contains 150 to $300 \mathrm{mg}$ of $\delta 9-\mathrm{THC}$ [94, 95]; for this reason, smokers today have greater risk of intoxicating effects from high doses than users 30 years ago. On the other hand, abuse during childhood and adolescence affects the maturation of neuronal circuits and increases the risk of suffering from mental illnesses, which is why its legalization is not justified. On the other hand, social groups that propose an allowed consumption of small quantities for personal use defend that it is a safe, misclassified, and benign drug, that has been prosecuted for its commercialization and possession. They also argue that in terms of economic and health costs for society, alcohol and tobacco cause a greater damage to collective and individual health than marijuana, which is debatable-this position is absurd because it posits that the right thing to do is to legalize a third drug. In the Netherlands, $C$. sativa is legally available in Dutch licensed drugstores, following pharmaceutical standards supervised by the Office of Medicinal Cannabis, which depends on the Dutch Ministry of Health [96].

Its consumption is punished and its possession for personal use (up to $5 \mathrm{~g}$ ) has the lowest judicial priority. The sale of $5 \mathrm{~g}$ (per buyer/day) is not usually investigated and the maximum "stock" allowed is $500 \mathrm{~g}$ per business. In contrast, a possession greater than $5 \mathrm{~g}$ is punished (30 days in jail); sale and use marketing are forbidden. In other countries, the possession of small amounts of Cannabis for medical use is tolerated, for example, in Spain, Belgium, and some regions in Switzerland. In Canada, it is possible to ask for an exemption certificate for medical use, which otherwise would be illegal. In addition, the ministry of health (Health Canada) sells Cannabis plants to patients if they do not want to grow them themselves. In the case of California, USA, a first time possession of small amounts (smaller than one $0 z, 28.5 \mathrm{~g}$ ), is considered as a minor offense that do not deserve detention, although it is punishable by a 100 dollars fine. Possession of larger amounts is punished with six months in jail and a 500 dollars fine. Officially authorized patients and providers can possess it and grow it, but cannot sell nor distribute it-they can only do it under medical recommendation or approval [97]. However, 15 states and one district in the American Union to date allow its medical use. In some of them, doctors have the prerogative to recommend medical marijuana to patients with cancer and HIV, or to indicate their patients where to acquire it. In this country, medical research continues to progress; research-grade Cannabis for specific protocols can be acquired. Until today, it is informed that more than 350 research protocols about marijuana medical properties are in official course. Marijuana that is administered orally (or rectally) has therapeutic properties in terminal-phase patients; and it can even be regarded as the first actually useful anti-suffering drug [98]. It is worth noting that the medicinal use of marijuana is legal in other countries, among them Germany, Argentina, Austria, Canada, Spain, Finland, Israel, Portugal, and eleven states of the United States (Alaska, California, Colorado, Hawaii, Maine, Montana, Nevada, Oregon, Rhode Island, Vermont, and Washington) have legalized the medicinal use of Cannabis under their state laws, but it is still illegal at the federal level $[99,100]$. In Uruguay, controlled used was recently approved. Lastly, no human deaths have been reported in association to Cannabis consumption since it has a very low toxicity. At the international level, the debate over marijuana has been centered around its medicinal use and several initiatives establishing its efficient and safe use against mortal diseases like cancer and HIV are undergoing [101, 102]. 


\section{CONCLUSION}

The therapeutic effects of cannabinoids are used in the treatment of neuropathic, oncologic and symptomatic pain in multiple sclerosis in patients unresponsive to usual treatments, epilepsy, spasticity (related to multiple sclerosis), Huntington's disease or medullary lesions, AIDS and terminal cancer, nausea, chemotherapy-induced vomiting, itching, allergies, psychiatric symptoms, and motility conditions. Marijuana that is administered orally (or rectally) is used in patients in terminal phase; it is actually a truly useful antisuffering drug. Cannabinoids like $\delta 9$-tetrahydrocannabinol are found naturally in the Cannabis sativa plant. Some compounds like nabilone, rimonabant, and levonantradol have been synthesized, and inside the organism there are endogenous cannabinoids, or endocannabinoids, such as anandamide, 2-arachidonoylglycerol, 2-arachidonoyl-glycerol ether, $\mathrm{O}$-arachidonoyl-ethanolamine and $\mathrm{N}$-arachidonoyl-dopamine, that are part of the endocannabinoid system and participate in the regulation of motor activity, learning, memory and nociception. The progress of scientific research has permitted the identification of molecular targets activated or inhibited by these substances, targets that are part of the inter-cellular communication endogenous cannabinoid system, especially active in the CNS, and that as many other systems is susceptible to pharmacological manipulation. In vitro tissue culture biotechnology could be projected as an efficient tool to produce cannabinoids in a safe way. In the United States and several European countries, the debate over marijuana is centered around its medicinal use and many initiatives in other countries are in operation or recognize and establish its efficacy and safeness in some of the mortal diseases, for example: multiple sclerosis, arthritis, epilepsy, glaucoma, HIV, chronic pain, Alzheimer's disease and cancer.

Funding: "This research received no external funding".

Acknowledgments: We thank the National Council of Science and Technology of Mexico (CONACyT) for the postdoctoral fellowship grant for the realization of this project. We thank Dr. Victor Rogelio Hernández Marroquín for supervising and reviewing this article.

Conflicts of Interest: "The authors declare no conflict of interest."

\section{REFERENCES}

1. Page EP, Nagel. Biosynthesis of terpenophenolic metabolites in hop and cannabis. Recent Adv Phytochemistry. 2006 40;179-0.

2. Cheng HD, Xiao-Jie G, Gen XP. Phytochemical and biological research of cannabis pharmaceutical resources. In: Cheng HD, Xiao-Jie G, Gen XP, editor. Medicinal Plants. Chemistry, Biology and Omics. United Kingdom: Woodhead Publishing; 2015. p. 431-464.

3. Lorenzetti V, Cousinjn J, Solowij N, Garavan H, Suo C, Yucel M, Verdejo-García A. The neurobiology of Cannabis use disorders: a call for evidence. Front Behav Neurosci. 2016 May;10:1-3.

4. Koltai H, Poulin P, Namdar D. Promoting cannbis proudcts to pharmaceutical drugs. European J Pharm Sci. 2019 Apr;132:118-0.

5. Kogan NM, Mechoulam R. Cannabinoids in health and disease. Dialogues Clin Neursoci. 2007 Jun;9:413-0.

6. Croxford JL. Therapeutic potential of cannabinoids in CNS disease. CNS Drugs. 2003 Jun;17:179-2.

7. Mackie K. Cannabinoid receptors as therapeutic targets. Annu Rev Pharmacol Toxicol. 2006 Jan;46:101-2.

8. MacCalluma CA, Ethan B. Russo BE. Practical considerations in medical cannabis administration and dosing. Eur J Case Rep Intern Med. 2018 Mar;49:12-9.

9. Guindon J, Hohmann A. The endocannabinoid system and pain. CNS Neurol Disord Drug Target. 2009 Jun;8:4031.

10. Grotenhermen F. Effects of cannabis and the cannabinoids. In: Grotenhermen F, Russo E, editor. Pharmacology, Toxicology and Therapeutic Potential, New York: The HaworthPress; 2002. 55-66 p.

11. Walsh D, Nelson KA, Mahmoud FA. Established and potential therapeutic applications of cannabinoids in oncology. Support Care Cancer. 2003 Mar;11:137-3.

12. Chandra S, Lata H, Khan IA, EISohly MA. Propagation of elite Cannabis sativa L. for the production of delta9tetrahydrocannabinol (THC) using biotechnological tools. In: Arora R, editor. Medicinal Plant Biotechnology. USA: Arora; 2010. 98-114. p.

13. Andre CM, Jean-Francois H, Guerriero G. Cannabis sativa: the plant of the thousand and one molecules. Front Plant Sci. 2016 Feb;7:1-7.

14. Bilodeau SE, Bo-Sen W, Anne-Sophie R, MacPherson S, Lefsrud M. An Update on plant photobiology and implications for cannabis production. Front Plant Sci. 2019 Mar;10:1-5.

15. Lanyon VS, Turner JC, Mahlberg PG. Quantitative analysis of cannabinoids in the secretory product from captitatestalked glands of Cannabis sativa L. (Cannabaceae). Bot Gaz. 1981 Sep;142:316-9. 
16. Elsohly MA, Slade D. Chemical constituients of marijuana: the complex mixture of natural cannabinoids. Life Sci. 2005 Dec;78:539-8.

17. Maroon J, Bost J. Review of the neurological benefits of phytocannabinoids. Surg Neurol Int. 2018 Apr;9:91-3.

18. Turner CE, Elsohly MA, Boeren EG. Constituent of Cannabis Sativa L. A review of the natural constituent. J Nat Prod. 1989 Mar;43:169-4.

19. Zuardi AW, Crippa JAS, Hallak JEC, Moreira FA, Guimarães FS. Cannabidiol, a Cannabis sativa constituent, as an antipsychotic drug. Braz J Med Biol Res. 2006 Apr;39:421-9.

20. Pertwee RG. Cannabinoid receptors and pain. Prog Neurobiol. 2001 Apr;63:569-1.

21. Pertwee RG. Cannabinoid receptor ligands: clinical and neuropharmacological considerations, relevant to future drug discovery and development. Expert Opin Investig Drugs. 2000 Jul;9:1153-1.

22. Kumar R, Chambers W, Pertwee RG. Pharmacological actions and therapeutic uses of cannabis and cannabinoids. Anaesthesia. 2001 Nov;56:1059-8.

23. Novak J, Zitterl-Eglseer K, Deans SG, Franz CM. Essential oils of different cultivars of Cannabis sativa L. and their antimicrobial activity. Flavour Fragr J. 2001 Jul;16:259-2.

24. McPartland JM, Russo EB. Cannabis and cannabis extracts: greater than the sum of their parts?. J Cann Therap. 2001 Dec;1:103-2.

25. Gagne SJ, Stout JM, Liu E, Boubakir Z, Clarck SM, Page JE. Identification of olivetolic acid cyclase from Cannabis sativa reveals a unique catalytic route to plant polyketides. Proc Natl Acad Sci USA. 2012 Jul;109:12811-6.

26. Marks D, Tian L, Wenger J, Omburo S, Soto-Fuentes W, He J, Gang D, Weiblen G, Dixon R. Identification of candidate genes affecting $\Delta 9$-tetrahydrocannabinol biosynthesis in Cannabis sativa. J Exp Bot. 2009 Sep;60:37156.

27. Pertwee RG. Cannabinoid pharmacology: the first 66 years. Br J Pharmacol. 2006 Jan;147:163-1.

28. Zou S, Kumar U. Cannabinoid receptors and the endocannabinoid system: signaling and function in the Central Nervous System. Int J Mol Sci. 2018 Mar;19:1-3.

29. Howlett A, Breivogel C, Childers S, Deadwyler S, Hampson R, Porrino L. Cannabinoid physiology and pharmacology: 30 years of progress. Neuropharmacol. 2004 Jan;47:345-8.

30. Console-Bram L, Marcu J, Abood M E. Cannabinoid receptors: nomenclature and pharmacological principles. Prog Neuropsychopharmacol Biol Psychiatry. 2012 Jul;38:4-5.

31. Kendall DA, Yudowski GA. Cannabinoid Receptors in the Central Nervous System: Their Signaling and Roles in Disease. Front Cell Neurosci. 2016 Jan;10:1-0.

32. Lutz B, Marsicano G. Endocannabinoid role in synaptic plasticity and learning. Encyclopedia of Neuroscience. 2009 Jan;963-5.

33. Silver RJ. The endocannabinoid system of animals. Animals (Basel). 2019 Sep;9:1-5.

34. Guzman M. Cannabinoids: potential anticancer agents. Nature Rev Cancer. 2003 Oct;3:745-5.

35. Gonçalves J, Rosado T, Soares S, Simão AY, Caramelo D, Luís A, Fernández N, Barroso M, Gallardo E, Duarte AP. Cannabis and its secondary metabolites: their use as therapeutic drugs, toxicological aspects, and analytical determination. Medicines (Basel). 2019 Mar;6:1-7.

36. Bradley E. Alger, Jimok Kim. Supply and demand for endocannabinoids. Trends Neurosci. 2011 Jun;34:304-5.

37. Soderstrom K, Soliman E, Van Dross R. Cannabinoids modulate neuronal activity and cancer by cb1 and cb2 receptor-independent mechanisms. Front Pharmacol. 2017 Oct;8:1-8.

38. Guindon J, Hohmann AG. The endocannabinoid system and pain. CNS Neurol Disord Drug Targets. 2009 Dec;8:403-1.

39. Ghosh S, Preet A, Groopman JE, Ganju RK. Cannabinoid receptor CB2 modulates the CXCL12/CXCR4-mediated chemotaxis of T lymphocytes. Mol Immunol. 2006 Jul;43:2169-9.

40. Ligresti A, Bisogno T, Matias I, De Petrocellis L, Cascio MG, Cosenza V, D'argenio G, Scaglione G, Bifulco M, Sorrentini I, Di Marzo V. Possible endocannabinoid control of colorectal cancer growth. Gastrenterol. 2003 Sep;125:677-7.

41. Ligresti A, Petrosino S, Di Marzo V. From endocannabinoid profiling to endocannabinoid therapeutics. Curr Opin Chem Biol. 2009 Jun;13:321-1.

42. Gaoni Y, Mechoulam R. Isolation, structure and partial synthesis of an active constituent of hashish. J Amer Chem Soc. 1964 Apr;86:1646-7

43. Martínez GL, Tacoronte MJE, Nuñez FY, McKallip RJ. Targeting CB2 cannabinoid receptors as a novel therapy to treat malignant lymphoblastic disease. Blood. 2002 Jul;100:627-4.

44. Kogan NM, Mechoulam R. Cannabinoids in health and disease. Dialogues Clin Neursoci. 2007 Dec;9:413-0.

45. Ujváry I, Hanuš L. Human metabolites of cannabidiol: a review on their formation, biological activity, and relevance in therapy. Cannabis Cannabinoid Res. 2016 Mar;1:90-1. 
46. Weston-Green K. The united chemicals of cannabis: beneficial effects of cannabis phytochemicals on the brain and cognition. In: Advances in Cannabinoid Research. Willard JC, Laprairie RB, editor. Ukraine: IntechOpen; 2018. 1-19p.

47. Schwilke EW, Schwope DM, Karschner EL, Lowe RH, Darwin WD, Kelly DL, Goodwin RS, Gorelick DA, Huestis MA. $\Delta^{9}$-Tetrahydrocannabinol (THC), 11-hydroxy-THC, and 11-nor-9-carboxy-THC plasma pharmacokinetics during and after continuous high-dose oral THC. Clin Chem. 2009 Dec;55:2180-9.

48. Andre CM, Hausman JF, Guerriero G. Cannabis sativa: The plant of the thousand and one molecules. Front Plant Sci. 2016 Feb;7:1-17.

49. Lanyon VS, Turner JC, Mahlberg PG. Quantitative analysis of cannabinoids in the secretory product from captitatestalked glands of cannabis sativa L. (cannabaceae). Bot Gaz. 1981 Sep;142:316-9.

50. Schindler F, Anghelescu I, Regen F, Jockers-Scherubl M. Improvement in refractory obsessive compulsive disorder with dronabinol. Am J Psychiatry. 2008 Apr;165:536-7.

51. Munson AE, Harris LS, Friedman MA, Dewey WL, Carchman RA. Antineoplastic activity of cannabinoids. J Natl Cancer Inst. 1975 Sep;55:597-2.

52. Galve-Roperh I, Galve-Roperh I, Sánchez C, Cortés ML, Gómez PT, Izquierdo M, Guzmán M. Anti-tumoral action of cannabinoids: involvement of sustained ceramide accumulation and extracellular signal-regulated kinase activation. Nature Med. 2000 Mar;6:313-9.

53. Sanchez C, Galve-Roperh I, Canova C, Brachet P, Guzman M. $\Delta 9$-Tetrahydrocannabinol induces apoptosis in C6 glioma cells. FEBS Lett. 1998 Sep;436:6-0.

54. Sanchez C, de Ceballos ML, del Pulgar GT, Rueda D, Corbacho C, Velasco G, Galve-Ropher I, Huffman W, Ramon $\mathrm{S}$, Guzmán M. Inhibition of glioma growth in vivo by selective activation of the CB2 cannabinoid receptor. Cancer Res 2001. Aug;61:5784-9.

55. Jacobsson SO, Rongard E, Stridh M, Tiger G, Fowler CJ. Serum-dependent effects of tamoxifen and cannabinoids upon C6 glioma cell viability. Biochem Pharmacol. 2000 Dec;60:1807-3.

56. Bifulco M, Laezza C, Portella G, Vitalle M, Orlando P, De Petrocellis L, Di Marzo V. Control by the endogenous cannabinoid system of ras oncogene-dependent tumor growth. FASEB J. 2001 Dec;15:2745-7.

57. Casanova ML, Blázquez C, Martínez-Palacio J, Villanueva C, Fernández-Aceñero MJ, Huffman JW, Jorcano JL, Guzmán M. Inhibition of skin tumor growth and angiogenesis in vivo by activation of cannabinoid receptors. J Clin Invest. 2003;111:43-0

58. Mon MJ, Jansing RL, Doggett S, Stein JL, Stein GS. Influence of $\Delta 9$-tetrahydrocannabinol on cell proliferation and macromolecular biosynthesis in human cells. Biochem Pharmacol 2008. 1978, 27, 1759-1765

59. Blevins RD, Smith DP. Effects of $\Delta-9$-tetrahydrocannabinol on cultured HeLa cell growth and development. Growth. 1980 Jun;44:133-8.

60. De Petrocellis L, Melck D, Palmisano A, Bisogno T, Laezza C, Bifulco M, Di Marzo V. The endogenous cannabinoid anandamide inhibits human breast cancer cell proliferation. Proc Natl Acad Sci USA. 1998 Jul;95:8375-0.

61. Melck D, Rueda D, Galve-Roperh I, De Petrocellis L, Guzmán M, Di Marzo V. Involvement of the cAMP/protein kinase A pathway and of mitogen-activated protein kinase in the antiproliferative effects of anandamide in human breast cancer cells. FEBS Lett. 1999 Dec;463:235-0.

62. Melck D, De Petrocellis L, Orlando P, Bisogno T, Laezza C, Bifulco M, Di Marzo V. Suppression of nerve growth factor trk receptors and prolactin receptors by endocannabinoids leads to inhibition of human breast and prostate cancer cell proliferation. Endocrinol. 2000 Jan;141:118-6.

63. Mimeault M, Pommery N, Wattez N, Bailly C, Henichart JP. Anti-proliferative and apoptotic effects of anandamide in human prostatic cancer cell lines: implication of epidermal growth factor receptor down-regulation and ceramide production. Prostate. 2003 Jun;56:1-2.

64. Ruiz LMA, Díaz-Laviada I. $\triangle 9$-tetrahydrocannabinol induces apoptosis in human prostate PC-3 cells via a receptorindependent mechanism. FEBS Lett. 1999 Sep;458:400-4.

65. Ligresti A, Bisogno T, Matias I, De Petrocllis L, Cascio MG, Cosenza V, D'argenio G, Scaglione G, Bifulco M, Sorrentini I, Di Marzo V. Possible endocannabinoid control of colorectal cancer growth. Gastrenterology. 2003 Sep;125:677-7.

66. Ligresti A, Petrosino S, Di Marzo V. From endocannabinoid profiling to endocannabinoid therapeutics. Curr Opin Chem Biol. 2009 Jun;13:321-1.

67. Chakravarti B, Ravi J, Ganju RK. Cannabinoids as therapeutic agents in cancer: current status and future implications. Oncotarget. $2014 \mathrm{Jul} ; 5: 5852-2$.

68. Agurell S, Halldin M, Lindgren J, Ohlsson A, Widman M, Gillespie H, Hollister L. Pharmacokinetics and metabolism of ácido $\triangle 9-\mathrm{THC}$ and other cannabinoids with emphasis on man, Pharmacol Rev. 1986 Mar;38:2.

69. Williams P.L., Moffat A.C. Identification in human urine of d9-tetrahydrocannabinol-11-oic acid glucuronide: a tetrahydrocannabinol metabolite. J Pharm Pharmacol. 1980 Jul;32:445-8. 
70. Huestis MA, Mitchell JM, Cone EJ. Urinary excretion of 11-nor-9-carboxy- $\delta 9$ tetrahydro cannabinol in humans after single smoked doses of marihuana. J Anal Toxicol. 1996 Oct;20:441-2.

71. Agurell S, Halldin M, Lindgren J, Ohlsson A, Widman M, Gillespie H, Hollister L. Pharmacokinetics and metabolism of ácido $\triangle 9-\mathrm{THC}$ and other cannabinoids with emphasis on man. Pharmacol Rev. 1986 Mar;38:21-2.

72. Harvey DJ. Oxidative cleavage of the pentyl side-chain of cannabinoids. Drug Metab Dispos. 1990 May;18:350-5.

73. Matsunaga T, Iwawaki $\mathrm{Y}$, Watanabe K, Yamamoto I, Kageyama T, Yoshimura T. Metabolism of $\delta 9$ tetrahydrocannabinol by cytochrome P-450 isozymes purified from hepatic microsomes of monkeys. Life Sci. 1995 May;56:2089-5.

74. Harvey DJ. Chemistry, metabolism and pharmacokinetics of the cannabinoids. In: Nahas GG, editor. New York: Raven Press; 1984. 37-107.p.

75. Harvey DJ. Metabolism and pharmacokinetics of the cannabinoids. In: Watson RR, editor. Biochemistry and Physiology of Substance Abuse. Boca Raton: CRC Press; 1991. 279-365. p.

76. Harvey DJ, Mechoulam R. Metabolites of cannabidiol identified in human orine. Xenobiotica. 1990 Mar;20:303-0.

77. Brown NK, Harvey DJ. Comparative in vitro metabolism of cannbinol in rat, mouse, rabbit, guinea pig, hamster, gerbil and cat. Eur J Drug Metab Pharmacokinetics. $1990 \mathrm{Jul} ; 15: 253-8$.

78. Dubin AE, Patapoutian A. Nociceptors: the sensors if the pain pathway. J Clin Invest. 2010 Nov;120:3760-2.

79. Basavaraiappa BS, Nixon RA, Arancio O. Endocannabinoid system: emerging role from neurodevelopment to neurodegeneration. Mini Rev Med Chem. 2009 Apr;9:448-2.

80. Bonhaus DW, Chang LK, Kwan J, Martin JGR. Dual activation and inhibition of adenylyl cyclase by cannabinoid receptor agonists: evidence for agonist-specific trafficking of intracellular responses. J Pharmacol Exp Ther. 1998 Dec;287:884-8.

81. Vuckovic S, Srebro D, Savic VK, Vucetic C, Prostran M. Cannabinoids and pain: new insights from old molecules. Front Pharmacol. 2018 Nov;9:1-9.

82. Maccarrone M, Lorenzon T, Bari M, Melino G, Finazzi-Agro A. Anandamide induces apoptosis in human cells via vanilloid receptors", Evidence for a protective role of cannabinoid receptors. J Biol Chem. 2000 Oct;275:31938-5.

83. Khan MI, Sobocinska AA, Czarnecka AM, Krol M, Botta B, Szczylik C. The therapeutic aspects of the endocannabinoid system (ECS) for cancer and their development: from nature to laboratory. Curr Pharm Des. 2016 Mar;22:1756-6.

84. Pertwee RG. Cannabinoid receptors and pain. Prog Neurobiol. 2001 Apr;63:569-1.

85. Gagnea S, Stouta J, Liua E, Boubakira Z, Clarka S, Pagea J. Identification of olivetolic acid cyclase from Cannabis sativa reveals a unique catalytic route to plant polyketides. Proc Natl Acad Sci USA. 2012 Jul;109:12811-6.

86. EISohly MA. Marijuana and the cannabinoids. In: EISohly MA, editor. Forensic Science and Medicine, New Jersey: Humana Press Inc; 2007. 322. p.

87. Turner CE, Elsohly MA, Boeren EG. Constituent of Cannabis Sativa L. A review of the natural constituent. J Nat Prod. 1989 Mar;43:169-4.

88. Walsh D, Nelson KA, Mahmoud FA. Established and potential therapeutic applications of cannabinoids in oncology. Support Care Cancer. 2003 Mar;11:137-3.

89. McPartland JM, Russo EB. Cannabis and cannabis extracts: greater than the sum of their parts?. J Cann Therap. 2001 Dec;1:103-2

90. Pertwee RG. Cannabinoid receptor ligands: clinical and neuropharmacological considerations, relevant to future drug discovery and development. Expert Opin Investig Drugs. 2000 Jul;9:1553-1.

91. Zuardi AW, Crippa JAS, Hallak JEC, Moreira FA, Guimarães FS. Cannabidiol, a Cannabis sativa constituent, as an antipsychotic drug. Braz J Med Biol Res. 2006 Apr;39:421-9.

92. Machado RFC, Stéfano SC, De Cássia HR, Rosa OLMQ, Da Silveira DX. Therapeutic use of Cannabis sativa on chemotherapy-induced nausea and vomiting among cancer patients: systematic review and meta-analysis. Eur $\mathrm{J}$ Cancer Care. 2008 Sep;17:431-3.

93. Torres G, Fiestas F. Efectos de la marihuana en la cognición: una revisión desde la perspectiva neurobiológica. Rev Peru Med Exp Salud Publica. 2012 Feb;29:127-4.

94. Ashton $\mathrm{CH}$. Pharmacology and effects of cannabis: a brief review. Brit J Psychiat. $2001 \mathrm{Feb} ; 178: 101-6$.

95. Howlett A, Breivogel C, Childers S, Deadwyler S, Hampson R, Porrino L. Cannabinoid physiology and pharmacology: 30 years of progress. Neuropharmacol. 2004 Jan;47:345-8.

96. Kumar R, Chambers W, Pertwee RG. Pharmacological actions and therapeutic uses of cannabis and cannabinoids. Anaesthesia. 2001 Nov;56:1059-8.

97. Grotenhermen F. Los cannabinoides y el sistema endocannabinoide. Cannabinoids. 2006 Sep;1:10-4.

98. Mccleod J, Oakes R, Copello A, Crome I, Egger M, Hickman M, Oppenkowski T, Stokes-Lampard H, Smith GD. Psychological and social sequelae of cannabis and other illicit drug use by young people: a systematic review of longitudinal, general population studies. Lancet. 2004 May;363:1579-8. 
99. Degenhardt L, Wall W. The association between psychosis and problematic drug use among Australian adults: findings from the National Survey of Mental Health and Well Being. Psychol Med. 2001 May;31:659-8.

100. Alger BE, Kim J. Supply and demand for endocannabinoids. Trends Neurosci. 2011 Jun;34:304-5.

101. Degenhardt L, Chiu W, Sampson N, Kessler RC, nthony JC, Angermeyer M, Bruffaerts R, de Girolamo G, Gureje O, Huang Y, Karam A, Kostyuchenko S, Lepine JP, Medina MME,Neumark Y, Ormel JH, Pinto-Meza A, PosadaVilla J, Stein DJ, Takeshima T, Wells JE. Toward a global view of alcohol, tobacco, cannabis, and cocaine use: findings from the WHO world mental health surveys. Plos Med. 2008 Jul;5:1053-7.

102. Croxford JL. Therapeutic potential of cannabinoids in CNS disease. CNS Drugs. 2003 Jun;17:179-2.

(C) 2020 by the authors. Submitted for possible open access publication under the terms and conditions of the Creative Commons Attribution (CC BY NC) license (https://creativecommons.org/licenses/by-nc/4.0/). 